\title{
¿Indemnización por la no realización del hecho del tercero o resarcimiento por incumplimiento de la promesa del hecho del tercero?
}

\author{
Rómulo Morales Hervias*
}

\section{Introducción}

La promesa del hecho de un tercero es un contrato por el cual una parte, denominada promitente, promete a la otra parte, denominada promisario, que un tercero realizará un hecho y pagará una «indemnización» si el tercero no realiza el hecho La pregunta que surge inmediatamente es si la promesa del hecho del tercero es una "obligación". La respuesta a esta pregunta es muy importante porque si es una obligación deberemos determinar si es una de medios o de resultados. Si es una obligación de medios, el promitente deberá probar que ha sido diligente para exonerarse de la obligación de «indemnizar» en el supuesto de que el tercero no realice el hecho. Si es una obligación de resultado, el promitente solamente se exonerará de responsabilidad si el tercero no pudo hacer el hecho por caso fortuito o fuerza mayor. También es muy importante determinar si realmente existe una "obligación de indemnizan o una "obligación de resarcimiento" en el caso que el tercero no realice el hecho. En un caso, aplicaremos las reglas del contrato como los contratos de seguros y, en el otro caso, las reglas de la responsabilidad por incumplimiento de obligaciones.

Hay algunas cuestiones que la doctrina admite sobre la promesa del hecho de un tercero. La primera cuestión es que la promesa del hecho de un tercero tiene «una eficacia sólo entre el promitente y el promisario y no puede en algún modo vincular al tercero». ${ }^{1}$ Otra cuestión es que "la promesa puede constituir objeto de un autónomo contrato, así como puede

* Abogado. Magíster por la Universidad di Roma «Tor Vergata». Profesor de Derecho Civil en la Pontificia Universidad Católica del Perú y en la Universidad de Lima.

1 FranzonI, Massimo. "ll contratto e i terzi». En Trattato dei contratti. Turín: Unione Tipografico-Editrice Torinese-UTET, 1999, tomo segundo, p. 1063. 
simplemente constituir objeto de una cláusula contractual. No obstante, el uso del sustantivo "promesa" puede corresponder a la figura del acto unilateral, ella va entendida como sinónimo de contrato».2

El presente estudio propondrá una reformulación de los conceptos de 'derecho de crédito', 'obligación', 'derecho potestativo', 'tutela jurídica sustancial', 'resarcimiento' e 'indemnización' en el marco del contrato de promesa del hecho de un tercero.

\section{Naturaleza jurídica de la promesa del hecho de un tercero}

El Código Civil peruano ${ }^{3}$ (en adelante CC) regula la promesa del hecho de un tercero en los artículos 1470 al 1472 .

El artículo $1470^{4}$ establece un hecho jurídico abstracto que es la promesa de la obligación o del hecho de un tercero, y por otro lado, señala un efecto jurídico abstracto que es la «obligación" del promitente de «indemnizar" al otro contratante si el tercero no asume la obligación o no cumple el hecho prometido. Esta indemnización a cargo del promitente tiene el carácter de prestación sustitutoria de la obligación o del hecho del tercero conforme el artículo $1471,{ }^{5}$ y puede pactarse anticipadamente el monto de esta conforme el artículo $1472 .^{6}$

Estas normas tienen como fuente directa el Código Civil italiano ${ }^{7}$ que regula la promesa del hecho de un tercero, y que subraya que el promitente se obliga a "indemnizar" al otro contratante si el tercero no efectúa el hecho prometido. La doctrina ha expresado que la «[...] obligación del hecho del tercero es aquella que obliga al deudor al comportamiento ajeno. El deudor, precisamente, está obligado a que un tercero tenga un cierto

2 Franzoni, op. cit., p. 1063.

3 El Código Civil fue promulgado por Decreto Legislativo 295, publicado el 25 de julio de 1984 en el diario oficial El Peruano y entró en vigencia el 14 de noviembre de 1984.

4 Artículo 1470 del Código Civil peruano.- «Se puede prometer la obligación o el hecho de un tercero, con cargo de que el promitente quede obligado a indemnizar al otro contratante si el tercero no asume la obligación o no cumple el hecho prometido, respectivamente".

5 Artículo 1471 del Código Civil peruano.- «En cualquiera de los casos del artículo 1470, la indemnización a cargo del promitente tiene el carácter de prestación sustitutoria de la obligación o del hecho del tercero".

6 Artículo 1472 del Código Civil peruano.- «Puede pactarse anticipadamente el monto de la indemnización".

7 Artículo 1381 del Código Civil italiano de 1942. Promesa de la obligación o del hecho del tercero.- «El que ha prometido la obligación o el hecho de un tercero está obligado a indemnizar al otro contratante si el tercero se niega a obligarse o si no cumple el hecho prometido". 
comportamiento negativo, estipulando o no estipulando un negocio jurídico, asumiendo una obligación, renunciando a un derecho, absteniéndose de una adquisición, exigiendo una obra de edificación en el propio fundo, etc.». ${ }^{8}$

Bajo la influencia de la codificación francesa, ${ }^{9}$ se ha sostenido que en la promesa del hecho del tercero existen dos obligaciones, una obligación principal cuya prestación implica persuadir al tercero para que el tercero haga el hecho y una obligación accesoria cuya prestación consiste en pagar una indemnización al promisario si el tercero no hizo el hecho. De la Puente ${ }^{10}$ sostiene que la

[...] obligación principal del promitente es una de medios, constituida por su deber jurídico de gestionar ante el tercero para que éste ejecute, a nombre propio, el hecho que tanto el promitente como el promisario desean que obtenga éste último. De esta manera, el promitente asume una obligación factible de cumplimiento, pues no se trata de prometer el hecho del tercero - que escapa de sus posibilidades-, sino de prometer que hará lo posible por persuadir al tercero para que ejecute el hecho, lo cual sí está dentro de su esfera jurídica de acción.

\section{Agrega que la}

[...] prestación accesoria sustituye a la principal por el solo hecho de no obtenerse el resultado prometido. Si el promitente ha actuado diligentemente se tendrá por cumplida su obligación principal con la ejecución de la prestación accesoria; si, por el contrario, no es diligente en el cumplimiento de su obligación principal de medios, deberá además ejecutar la prestación accesoria, indemnizar los daños y perjuicios que su negligencia haya causado al promisario. Similarmente si el promitente no actúa con diligencia en la ejecución de la prestación accesoria, deberá indemnizar al promisario los daños y perjuicios que con ello le cause. ${ }^{11}$

Luego, De la Puente hace una precisión en el sentido de que la expresión «indemnización» ha sido indebidamente utilizada en el texto del código civil,

8 Bianca, Massimo. Diritto civile, L'obbligazione. Milán: Giuffrè, 1999, p. 114. El autor cita la jurisprudencia italiana que califica como obligación del hecho del tercero el compromiso del vendedor de hacer obtener al comprador el certificado de habitabilidad: C. de 25 de febrero de 1987, n. 1991.

9 Artículo 1120 del Código Civil francés de 1804.- "Sin embargo, se puede estipular en nombre de un tercero, prometiendo la aprobación de éste, quedando a salvo el otro contratante, el derecho de indemnización contra el promitente, si el que hubiera de obligarse en primer término, se negare a ratificar el pacto». Es sintomático que el legislador francés haga referencia a la obligación que pudiera asumir el tercero.

10 De la Puente y Lavalle, Manuel. El contrato en general, Comentarios a la Sección Primera del Libro VII del Código Civil. Lima: Palestra Editores, 2001, tomo III, p. 262.

"Ibidem, pp. 263-264. 
[...] pues mediante la prestación sustitutoria no se busca indemnizar al promisario por la inejecución de la obligación principal de medios, sino simplemente reemplazar esta obligación, cuando el cumplimiento de ella es insuficiente para lograr el resultado, por una obligación accesoria o secundaria cuyo contenido es la prestación sustitutoria. La diligencia empleada en el cumplimiento infructuoso de la obligación principal no es óbice para que el promisario asuma la titularidad de la obligación accesoria y, en ejecución de ella, reciba la prestación sustitutoria. El promisario sólo tendrá derecho a indemnización por daños y perjuicios cuando el promitente sea negligente en el cumplimiento de la obligación principal, que es de medios, o en el de la accesoria, que en teoría puede ser de medios o de resultado, aunque generalmente sea de esta última clase. ${ }^{12}$

Esta posición debe ser criticada porque, en realidad, el promitente no asume una obligación de medios. Si fuera así, será suficiente que el promitente pruebe que fue diligente para cumplir con su obligación para evitar asumir la obligación accesoria. Si prueba su comportamiento diligente la obligación accesoria se extingue irremediablemente. ${ }^{13}$ Tampoco es correcto decir que la “indemnización" es una prestación accesoria. Hay una confusión entre el contrato de promesa del hecho del tercero con el contrato de fianza, el cual es accesorio del contrato principal. El autor refiere que la prestación accesoria sirve para «indemnizar los daños y perjuicios que su negligencia haya causado al promisario". Aquí notamos que el autor menciona el verbo «indemnizar» pero en realidad se está refiriendo al "resarcimiento", en el caso que el promitente incumpla con su «obligación principal de medios". En tal hipótesis, debemos aplicar las normas sobre la responsabilidad por incumplimiento de las obligaciones siempre y cuando el promisario haya sufrido un daño.

En efecto, para que proceda la «indemnización" es necesario que ocurran dos situaciones de hecho. En primer lugar, que el promitente actúe negligentemente; en segundo lugar, que el promisario sufra un daño. Si el promitente actúa con dolo y el promisario sufre un daño, el promitente no estará obligado porque ha asumido una «obligación principal de medios».

12 Ibidem, pp. 276-277.

13 ForNo Florez, Hugo. «Precisiones conceptuales en torno a la promesa de hecho ajeno". Advocatus, Lima, año III, Cuarta Entrega, 1992, p. 44 y p. 47: "Se le objeta que si la promesa se configura como una obligación cuya prestación consiste en desplegar el esfuerzo ordinario necesario para que el tercero se obligue o ejecute el hecho, según corresponda, la prestación queda ejecutada luego que el promitente realice tal esfuerzo con la debida diligencia, y en consecuencia la obligación se extingue por cumplimiento, y el deudor queda liberado, independientemente de si el tercero efectivamente asume la obligación o ejecuta el hecho de que se trate». Y más adelante lo corrobora: "En las obligaciones de medios, en efecto, al deudor le basta desplegar la conducta programada en la obligación con la diligencia ordinaria requerida, con lo cual habría quedado ejecutada su prestación". 
No es casualidad establecer que la "promesa de la obligación o del hecho de un tercero determina, si el tercero rechaza, la obligación del promitente al resarcimiento del dañom. ${ }^{14}$

A diferencia de la concepción de la obligación de medios, se sostiene que el contrato en referencia contiene una obligación de resultado:

\begin{abstract}
Quien promete el hecho del tercero se obliga en orden a un resultado, y la falta de realización de él constituye un incumplimiento de la obligación asumida. De tal incumplimiento el deudor responde salvo que el hecho del tercero sea impedido por un evento no previsible ni superable con el esfuerzo diligente que el promitente está obligado (por ejemplo: la quiebra del tercero). ${ }^{15}$
\end{abstract}

Tampoco pensamos que el contrato de promesa del hecho de un tercero contiene una obligación de resultado porque tal contrato sería nulo, pues el objeto del contrato sería imposible físicamente. En efecto, es imposible físicamente que el tercero haga el hecho porque el comportamiento que pudiera hacer el promitente para convencer al tercero es externo a la posibilidad de la realización del hecho de un tercero. ${ }^{16}$

El modelo que el contrato de promesa del hecho del tercero contiene una obligación

[...] llega a reconstruir la responsabilidad del promitente según el régimen del articulo $1218^{17}$ (con acentuaciones de menor o mayor rigor, según la obligación de hacer que el tercero preste ya sea como obligación de medios o de resultado): posibilitará al promitente mayores oportunidades para ofrecer cualquier eficaz prueba

14 Santoro-Passarelli, Francesco. Dottrine generali del diritto civile, novena edición. Nápoles: Casa Editrice Dott. Eugenio Jovene, 1997, pp. 127-128.

15 BIANCA, op. cit., p. 120.

16 FORNO, op. cit., p. 48: "Ahora bien, es conveniente puntualizar que el hecho de un tercero no puede concebirse como un resultado susceptible de establecerse como prestación a cargo del promitente porque se trata de un resultado cuya obtención no depende de la actividad o conducta del promitente, y por lo tanto no reúne el requisito de posibilidad que es esencial a toda prestación (de medios o de resultado)". No compartimos este argumento porque para nosotros la prestación es un elemento de la obligación pero los requisitos de la posibilidad, de la determinación, de la licitud y de la patrimonialidad están referidos al objeto del contrato: MORALES HERVIAS, Rómulo. «Objeto y tipo en las teorías del negocio jurídico y del contrato, A propósito de la reforma del Código Civil». Advocatus, nueva época, Lima, No 9, II, Lima, 2003, p. 242. Pero aceptamos que el requisito de la posibilidad es el aplicable para objetar a la teoría que sostiene que la promesa del hecho de un tercero contiene una obligación de resultado.

17 Artículo 1218 del Código Civil italiano de 1942. Responsabilidad del deudor.- "El deudor que no realiza exactamente la prestación debida está obligado al resarcimiento del daño a menos que pruebe que el incumplimiento o el retardo han sido determinados por imposibilidad de la prestación derivada de causa no imputable a él». 
liberatoria, alegando elementos que hagan no imputable al promitente la ausencia de prestación del tercero. ${ }^{18}$

Para otros, el contrato de promesa del hecho de un tercero es connatural "una garantía en cuya virtud la falta de la prestación convenida convierte, en determinadas hipótesis, el contenido de la obligación en un resarcimiento del daño (artículo 1381), es decir, en una prestación que es siempre posiblew. ${ }^{19}$ Así:

[...] en general la promesa del comportamiento de un tercero es convertida por la ley en una garantía que sólo obliga al promitente. Es decir, permite hacer del comportamiento del tercero condición (Wofür der Haftung, diría Brinz) de un contrato de garantía según la cual una parte se obliga frente a la otra a pagar una indemnización [indennità] para la hipótesis que el hecho del tercero no se realice (art. 1381). En todo caso, la relación de obligación se circunscribe a las partes del negocio y asume el hecho del tercero sólo como punto de referencia de la obligación a través de la contraparte: garantizando el hecho ajeno, el promitente no hace otra cosa, en resumen, que prometer el hecho propio y asume responder por su no realización (promete, como se decía en el Derecho común, de rato, alias de propio). Por lo que, si el promitente no asume realmente, sino que expresamente excluye, la garantía del hecho ajeno, que se concreta en una responsabilidad por daños, ha de considerarse que la sola promesa no crea un vínculo jurídico. ${ }^{20}$

Lo curioso del planteamiento de Betti es que menciona que la garantía es para resarcir daños. Y para que no quede duda, lo dice claramente en otra obra suya:

Ahora bien, en este caso, antes de que se produzca el daño, no podemos decir que haya una prestación en el sentido técnico tradicional, de una conducta valorable con un criterio de diligencia o de resultado útil de un obrar, sino que sólo hay una garantía, una seguridad prestada por la sociedad aseguradora por el solo hecho de haber asumido para sí el riesgo con la obligación de abonar una indemnización, o resarcir un eventual dańo al producirse el riesgo mismo. ${ }^{21}$

18 Roppo, Vincenzo. «ll Contratto». En Trattato di Diritto privato. Milán: Giuffrè, 2001, p. 571.

19 BETTI, Emilio. Teoria generale del negozio giuridico. Nápoles: Edizioni Scientifiche Italiane, 2002, p. 367.

20 BetTl, op. cit. pp. 549-550.

21 Betri, Emilio. Teoría general de las obligaciones. Traducción y notas de Derecho Español por José Luis de los Mozos. Madrid: Editorial Revista de Derecho Privado, 19691970, tomo II, p. 43. 
- En el mismo sentido de Betti, Forno ${ }^{22}$ sostiene que

[...]el riesgo puede definirse como la posibilidad de la ocurrencia de un daño a causa de la verificación (o no verificación) de un evento que lo produce. Entonces, la asunción de la obligación o la ejecución de un hecho por parte de un tercero, en cuanto que no puede concebirse como un resultado cierto producto del obrar del promitente, es decir como objeto de la obligación del promitente, puede más bien conceptualizarse precisamente como un riesgo (consistente en que el tercero no asuma la obligación o no ejecute el hecho) que determina la posibilidad de un daño en el promisario.

\section{Además:}

[...] toda relación de garantía, comprende, en primer lugar, la asunción de un riesgo, el cual se desplaza del promisario al promitente, y consiste en la probabilidad de la ocurrencia de un daño, en el caso en que no tenga lugar el evento esperado, o sea, la asunción de la obligación o la ejecución del hecho por parte del tercero. La asunción de este riesgo es un efecto automático y directo del contrato de promesa y no requiere, por tanto, de ninguna prestación a cargo del promitente. En segundo lugar, también comprende una obligación en sentido técnico, que es la obligación de indemnizar al promisario y que tiene como contenido una prestación de dar (una suma de dinero). ${ }^{23}$

Luego, se refiere que esta "obligación de indemnidad es no sólo futura sino también eventual porque depende que se produzca un daño en el promisario y esto, a su vez, depende de que tenga lugar el evento temido (que el tercero no ejecuta el hecho prometido)m. ${ }^{24}$

Quienes siguen el modelo de garantía, según el cual el promitente asume el riesgo de la ausencia del hecho de un tercero, no establecen con claridad la diferencia entre resarcimiento e indemnización:

[...] la responsabilidad del promitente puede desprenderse aun en los casos en que la falta de la prestación del tercero no sea imputable por su culpa. Por el contrario, esto no significa que al promitente le sea impedido alguna excepción liberatoria: también aplicando el modelo de la garantía, de modo que se debería permitir liberarse probando que el rechazo del tercero de obligarse o la falta de cumplimiento de

\footnotetext{
FORNO, op. cit., p. 48.

Ibidem, p. 49.

24 Ibidem, p. 50.
} 
su prestación son objetivamente justificados (al límite porque la obligación o la prestación se convierten en imposibles) y tanto más si dependen del hecho del promisario. ${ }^{25}$

Debemos anotar que si el hecho depende del promisario no estamos en el supuesto de un contrato de promesa del hecho de un tercero, y por eso se incurre en un error al identificar el resarcimiento y la indemnización. De esta manera, abiertamente se admite que el

[...] art. 1381 [del Código Civil italiano] dice «indemnizar» y no «resarcir». Sobre esta base, se ha sostenido que el promitente no debería al promisario el entero daño causado por la ausencia de prestación del tercero, sino respondería sólo en los límites del valor de la prestación ausente. En todo caso, la indemnización podrá reducirse ex art. $1227,{ }^{26}$ si el promitente demuestra un concurso de culpa del promisario. $^{27}$

Este mismo argumento de la imputabilidad de la culpa al promisario posiblemente se aplique a quienes siguen el modelo de la obligación. ${ }^{28}$ Pero otro sector de la doctrina unifica los modelos de la obligación y de la garantía. Por un lado, el hecho del tercero es objeto inmediato de la promesa efectuada porque «la inactividad constituye objeto propio de la obligación asumidan. ${ }^{29} \mathrm{Y}$ por otro lado, se dice que es un supuesto de contrato de garantía autónomo, en el sentido de que la promesa del hecho del tercero asume una "función sustitutiva, porque la prestación de garantía es diversa del resultado obtenible con la actividad del tercerom. ${ }^{30}$ Este modelo de unifi-

2. Ibidem, p. 572 .

26. Artículo 1227 del Código Civil italiano de 1942. Concurso del hecho culposo del acreedor.- "Si el hecho culposo del acreedor ha concurrido a ocasionar el daño, el resarcimiento se disminuye según la gravedad de la culpa y la dimensión de las consecuencias que han derivado de ella.

El resarcimiento no procede con respecto a los daños que el acreedor habría podido evitar con el empleo de la diligencia ordinaria». Esta norma ha sido la fuente de las siguientes normas del $\mathrm{CC}$, en el marco de la responsabilidad por incumplimiento de las obligaciones:

Artículo 1326.- Si el hecho doloso o culposo del acreedor hubiese concurrido a ocasionar el daño, el resarcimiento se reducirá según su gravedad y la importancia de las consecuencias que de él deriven.

Artículo 1327.- El resarcimiento no se debe por los daños que el acreedor habría podido evitar usando la diligencia ordinaria, salvo pacto en contrario».

27 RopPO, op. cit., p. 572.

zo GaZZONI, Francesco. Manuale di diritto privato. Nápoles: Edizioni Scientifiche Italiane, 2003, pp. 933-934.

29 Franzoni, op. cit., p. 1063.

30 Ibidem, p. 1065. 
cación es objetable porque une los argumentos que hemos objetado en los modelos de la obligación y de la garantía. Nuestra posición será diferente a la desarrollada por la doctrina según el marco teórico que formularemos a continuación.

\section{Derecho de crédito, obligación, derecho potestativo y tutela jurídica sustancial}

La situación jurídica subjetiva es la «situación, o posición, en que viene hallarse un sujeto, por efecto de la aplicación de una o más reglas de derecho. ${ }^{31}$ Se llama, en general, situación jurídica activa a aquella en que se halla la parte en ventaja, porque su interés está protegido por la relación, y situación jurídica pasiva aquella en que se halla la parte en desventaja, porque el interés es sacrificado". ${ }^{32}$ Un ejemplo nos puede ayudar a comprender estos conceptos. Por el contrato de hospedaje, ${ }^{33}$ el hospedante se obliga a prestar al huésped albergue, alimentación y otros servicios que contemplan la ley y los usos, a cambio de una retribución. El interés del hospedante de prestar alojamiento, alimentación y otros servicios está subordinado al interés del huésped de disfrutarlos, pero el interés del huésped de pagar la retribución está subordinado al interés del hospedante de recibirla. Por el contrario, el interés del huésped de recibir la habitación en las condiciones de aseo y funcionamiento de servicios normales y que los alimentos tengan la calidad e higiene adecuados ${ }^{34}$ es protegido en relación del interés del hospedante de prestarlos en tales condiciones. Como se puede observar, los sujetos

31 ZaTTI, Paolo. "Le situazioni giuridiche». En Linguaggio e regole del diritto privato, Nuovo manuale per $i$ corsi universitari, cuarta edición. Padua: Casa Editrice Dott. Antonio Milani, 2003, p. 47. Para el autor, la regla de derecho "es sólo aquella que se forma en uno de los modos de producción previstos por el mismo sistema», y las "reglas que regulan los modos de producción de las normas de un sistema jurídico se llaman normas de producción", op. cit., pp. 7-8. También véase ZATTI, Paolo. "Le situazioni giuridiche». En Lineamenti di diritto privato, novena edición. Padua: Casa Editrice Dott. Antonio Milani, 2003, p. 72.

32 ZATTl, op. cit., p. 47.

33 Artículo 1713 del Código Civil peruano.- «Por el hospedaje, el hospedante se obliga a prestar al huésped albergue $y$, adicionalmente, alimentación y otros servicios que contemplan la ley y los usos, a cambio de una retribución. Esta podrá ser fijada en forma de tarifa por la autoridad competente si se trata de hoteles, posadas $u$ otros establecimientos similares".

\$4 Artículo 1715 del Código Civil peruano.- «El huésped tiene derecho a exigir del hospedante que la habitación presente las condiciones de aseo y funcionamiento de servicios normales y que los alimentos, en su caso, respondan a los requisitos de calidad e higiene adecuados». 
ocupan posiciones como consecuencia de la realización o acaecimiento de hechos jurídicos y de la aplicación de las normas jurídicas. El contrato de hospedaje es un hecho jurídico que produce posiciones o situaciones jurídicas subjetivas. Nótese que el concepto de interés es fundamental para comprender las posiciones jurídicas de los sujetos. El «interés es, en efecto, necesidad de un bien, y el interés tutelado por el derecho se concreta en relación al bien idóneo para satisfacer tal interésm. ${ }^{35}$

La "situación subjetiva de la persona, que es obligada a un cierto comportamiento (a hacer o a no hacer alguna cosa: deber positivo o negativo) se llama deber" ${ }^{36}$ o la usituación de la persona que debe tener un cierto comportamiento; el que supone obviamente, que una norma jurídica califique la conducta de aquella persona como obligatoria». ${ }^{37} \mathrm{El}$ hospedante está obligado a prestar al huésped albergue, alimentación y otros servicios normales y adecuados; y el huésped está obligado a pagar una retribución.

Por otro lado, el derecho subjetivo indica la usituación jurídica de un sujeto a la cual una o más normas aseguran la posibilidad de satisfacer un cierto interés económico o moral; se habla por eso de derecho subjetivo: el concepto de derecho, así usado, resume el contenido de las normas desde el punto de vista del sujetor. ${ }^{38} \mathrm{El}$ hospedante tiene el derecho de satisfacer su interés a través de la retribución, y el huésped tiene el interés de disfrutar normales y adecuados alojamientos, alimentación y otros servicios.

El derecho de crédito es "una pretensión a una "prestación" que se puede valorar desde el punto de vista económico». ${ }^{39}$ Así, el deudor "debe realizar un comportamiento al cual está obligado; se halla por eso en una situación de deber o de obligación (deudor qui debet, que debe)». ${ }^{40}$ Tal comportamiento es la prestación que "«debe ser susceptible de valoración económica", aunque el interés, que se trata de satisfacer, no sea en sí y por si de naturaleza patrimonial». ${ }^{41}$ Además:

[...] debe repararse que, si aceptamos que en toda obligación existe siempre comprendido un resultado útil para el acreedor, deberá aceptarse también entonces que

35 BIANCA, Massimo. Diritto civile, La propietà. Milán: Giuffrè, 2001, p. 50.

3 ZATTI, Linguaggio..., p. 48.

3 ZATTI, Lineamenti..., p. 72.

3 Ibidem, p. 51. ZATTI, Lineamenti..., p. 78: «Sobre todo observamos que en todas las expresiones indicadas la palabra "derecho" es usada para indicar una posición del sujeto: la situación jurídica de una persona a la cual una norma asegura la posibilidad de satisfacer un cierto interés económico o moral; se habla por eso de derecho subjetivo".

* ZATI, Linguaggio..., p. 54. ZATTI, Lineamenti..., p. 83.

- ZATT, Linguaggio..., p. 55. ZATTI, Lineamenti..., p. 85.

4l ZATI, Linguaggio..., p. 56. ZATTI, Lineamenti..., p. 85. 
el interés de éste está centrado en dicha utilidad ante todo, por encima del esfuerzo que realice el deudor para procurarle dicha utilidad. La prestación sigue siendo entendida como un elemento vital en el concepto de obligación, pero ya no como fin de ésta, sino como el instrumento de cooperación a través del cual se procura al acreedor el resultado útil esperado. ${ }^{42}$

De esta manera es insostenible aplicar la distinción de las obligaciones de medios y de resultados porque la obligación contiene como elementos a la prestación y al interés del acreedor: "Con el término de "prestación" se tiene por eso consideración a la obtención del resultado (entendido como realización del interés creditorio) pero a través del comportamiento finalizado del deudom ${ }^{43}$ Aquí podemos indicar que la relación jurídica es aquel vínculo entre situaciones jurídicas subjetivas. ${ }^{44}$ Por ejemplo, la obligación de prestar al huésped albergue, alimentación y otros servicios normales y adecuados está relacionado con el derecho de disfrutar normales y adecuados alojamientos. Y la obligación de pagar una retribución está vinculado con el derecho de satisfacer su interés a través de la retribución: "Hay casos en que a un sujeto le es atribuido un poder al cual no le corresponde una obligación, pero si una sujeción: vale decir que el titular, ejercitando su poder, no hace valer una pretensión, sino determina directamente una modificación, en su propia ventaja, en la situación jurídica de la contrapartem. ${ }^{45} \mathrm{El}$ titular del derecho «tiene el poder de determinar un cambio de la situación jurídica, que la otra parte sufrem. ${ }^{46}$

El derecho potestativo es un derecho subjetivo que tiene por contenido la posibilidad de modificar unilateralmente la esfera jurídica de otro sujeto, para la satisfacción de un interés propio. Este derecho potestativo funciona como una pretensión material o sustancial.

Los conceptos de derecho de crédito y derecho potestativo son distintos ya que:

[...] la doctrina moderna se ha encargado de esbozar con suficiente nitidez la diferencia entre la deuda o deber como situación jurídica sujetiva de desventaja y el

42 Fernández CRUZ, Gastón. «Inimputabilidad en la inejecución de obligaciones». En Código Civil, Comentarios por los 100 mejores especialistas, Derecho de obligaciones. Primera edición. Lima: Gaceta Jurídica, 2004, tomo Vl, p. 861.

4 Di MAjO, Adolfo. "Delle obbligazioni in generale, Art. 1173-1176". En Commentario del Codice Civile Scialoja-Branca, Libro quarto- Delle obbligazioni. Bolonia: Nicola Zanichelli, 1988, p. 116.

44 BIANCA, Diritto civile, La propietà..., p. 10: "La relación jurídica puede ser definida como la síntesis de situaciones subjetivas correlativas".

45 ZaTtI, Linguaggio.... p. 55.

4. ZATTI, Lineamenti..., p. 84. 
correlativo derecho de crédito como situación jurídica subjetiva de ventaja, de un lado; y, del otro, la sujeción, que es otro tipo de situación jurídica subjetiva de desventaja y el derecho potestativo que es la correlativa situación jurídica subjetiva de ventaja. En efecto, el derecho de crédito —que es a su vez un tipo de derecho subjetivo, pero no el único- es una situación jurídica subjetiva de ventaja porque está concebido para procurar a su titular la satisfacción de un interés considerado jurídicamente relevante y que le sirve de presupuesto. Como todo derecho subjetivo, el crédito es una situación de ventaja activa porque confiere a su titular una facultad de obrar en los términos que más adelante esbozaremos. Sin embargo, el tipo de interés de que se trata no permite ser realizado con el puro obrar del titular del derecho, puesto que tal realización requiere necesariamente de la cooperación de la conducta de otro sujeto; por eso, el derecho de crédito no es una situación de ventaja autosuficiente. En consecuencia el ordenamiento prevé la creación de una situación jurídica subjetiva en aquel otro sujeto, situación que es de desventaja en tanto que coloca a su titular en una situación de necesidad consistente en realizar la conducta (prestación) que satisfará el interés del acreedor; en tanto que consiste en una necesidad de obrar, se trata de una situación subjetiva de desventaja activa. La facultad de obrar que el crédito le confiere al acreedor consiste en pretender y por tanto en exigir al deudor la realización de la conducta que satisfará el interés de aquél. La coordinación de estas dos situaciones jurídicas subjetivas configura la relación obligatoria. Por su parte, el derecho potestativo es también una situación jurídica subjetiva de ventaja en tanto que confiere a su titular una facultad en procura de la realización de un interés propio jurídicamente relevante. Tal facultad consiste en la posibilidad de obrar de manera que también se trata de un derecho subjetivo. Pero como el interés que sirve de presupuesto al derecho potestativo se realiza mediante la alteración de la realidad jurídica de otro sujeto, el ordenamiento reconoce dicha alteración como consecuencia del obrar del titular del derecho, de manera que éste puede satisfacer su propio interés directamente mediante el ejercicio de su propio derecho; por eso se dice que el derecho potestativo es autosuficiente. En este orden de ideas, no se requiere que otro sujeto desarrolle un comportamiento para satisfacer el interés del primero, sólo se requiere el reconocimiento por parte del ordenamiento de la alteración de su esfera jurídica como consecuencia del ejercicio del derecho por parte de su titular. En consecuencia la situación jurídica subjetiva de desventaja que se crea en el sujeto pasivo, no le impone deber alguno sino que lo somete inexorablemente a sufrir dicha alteración en el caso en que el titular del derecho decida ejercerlo y efectivamente lo haga; por esta razón esa situación se denomina de sujeción. ${ }^{47}$

De lo desarrollado, consideramos que ni el derecho de crédito ni el derecho potestativo son facultades. La facultad ues por eso la situación del sujeto que puede realizar licitamente un acto (al cual es lícito tener un com-

${ }^{47}$ FORNO FlOREZ, Hugo. "Los efectos de la oferta contractual". IUs et Veritas, año VIII, n." 15, pp. 183-197. 
portamiento descrito de la norma)». ${ }^{48} \mathrm{Y}$ poder es, por consiguiente, "la situación del sujeto que puede realizar eficazmente un acto (al cual le es otorgado de producir determinadas consecuencias jurídicas)»." "Facultad $y$ poder son por ello dos conceptos diversos: el primero indica la posición de aquél que puede realizar lícitamente un acto, el segundo la posición de quien puede realizar eficazmente un acto". ${ }^{50}$ Por ello, se dice con acierto que la "facultad no es, por tanto, una situación jurídica subjetiva autónoma sino uno de los modos a través de los cuales puede ejercitarse el derecho: ella por eso forma parte del contenido del derecho mismon. ${ }^{51}$ Un ejemplo claro es el derecho de propiedad que es un derecho subjetivo según el cual el interés protegido está relacionado al ejercicio de las facultades de usar y de disfrutar sobre el bien.

Por otro lado, la tutela jurídica sustancial de situaciones jurídicas subjetivas es el mecanismo de protección de estas, que opera cuando tales situaciones se lesionan o están en peligro. El titular de una situación jurídica subjetiva debe poder gozar de medios de tutela que protejan su posición jurídica cuando tal posición esté en peligro de lesionarse o cuando exista lesión efectiva de tal posición. ${ }^{52}$ Este concepto hace referencia a una "gama muy amplia de instrumentos de protección y actuación de las situaciones jurídicas subjetivas (no sólo derechos)». ${ }^{53}$ Este concepto tiene que ver con la efectividad del sistema jurídico, «es decir, la efectiva aplicación de las normas vigentes en el ordenamiento, y por eso de la efectiva realización de los equilibrios de los intereses que las reglas de derecho tienden a establecer». ${ }^{54}$

Estos remedios o mecanismos de tutela contienen el poder de pedir la protección efectiva cuando su posición jurídica está en peligro o ha sido lesionada. En este sentido, la categoría de pretensión procesal es irrelevante jurídicamente. El concepto de tutela jurídica sustancial es diametralmente diferente al concepto del derecho de acción. El derecho de acción es un poder jurídico que se dirige al órgano jurisdiccional para reclamar la prestación de la función jurisdiccional y obtener un pronunciamiento (sentencia). Este derecho es autónomo a la situación jurídica subjetiva existente y es abstracto porque cualquiera puede poner en movimiento la función jurisdiccional. Asimismo, se dice que el derecho de acción contiene una pretensión procesal la cual es la afirmación de una situación jurídica subjetiva y la reclamación de un pronunciamiento judicial. En el fondo la pretensión

48 ZATTI, Linguaggio..., p. 49. ZATTI, Lineamenti.., p. 73.

ZATTI, Linguaggio..., p. 49. ZATTI, Lineamenti.., p. 74.

ZATTI, Linguaggio..., p. 49. ZATT, Lineamenti..., p. 74.

GAZZONI, op. cit., p. 58.

Dı MAjo, Adolfo. La tutela civile dei diritti, tercera edición. Milán: Giuffrè, 2001, p. 4.

ZATTI, Linguaggio..., p. 121.

\$4 ZATTI, Lineamenti..., p. 187. 
procesal se reduce al poder jurídico que tiene el titular de una situación jurídica subjetiva cuando el ordenamiento jurídico le otorga mecanismos de protección. El derecho de acción no depende de la situación jurídica subjetiva ni tampoco está subordinado a la situación jurídica subjetiva. El derecho de acción es autónomo respecto a la situación jurídica subjetiva.

Siguiendo una teoría que relaciona las potestades y sujeciones, ${ }^{55}$ es importante expresar que

[...] entre poder y pretensión, entre sujeción y obligación no existe aquella señal que no se puede satisfacer plenamente, aquella contraposición que encontramos en el esquema conceptual de Hohfeld, ya que, en realidad, la única diferencia está dada por el hecho que la pretensión y la obligación están constituidas por poderes y sujeciones potenciales, que se combinan en una estructura compleja. Se piensa: aquí no se quiere sostener que el mencionado esquema es erróneo y debe ser abandonado. En efecto, no se puede negar, que entre obligación y sujeción existe la misma diferencia que encontramos entre la potencia y el acto. Y se comprende muy bien por qué motivo la pretensión aparece como un concepto muy diferente del poder en sentido estricto o de los denominados derechos potestativos: en el fondo, tal situación subjetiva activa es paradójicamente caracterizada por un estado de inercia (aún si es una inercia... llena de tensión) ya que el acreedor está destinado a "esperar" la prestación del deudor y sólo en caso de incumplimiento puede reaccionar con los poderes (ciertamente que invaden la ajena esfera jurídica) concedidos por el ordenamiento. Sin embargo, los mencionados poderes no son nada diferentes de la pretensión: constituyen el contenido, ya están en ella, también en el estado potencial..$^{56}$

Como se ha observado muy bien, en el fondo las tutelas jurídicas sustanciales tienen la estructura de "derechos potestativos sustanciales». ${ }^{57}$

\section{El seguro obligatorio de accidentes de tránsito. A propósito de la indemnización y del resarcimiento}

La Ley General de Transporte y Tránsito Terrestre ${ }^{58}$ (en adelante, ley 27181) diferencia con claridad los regímenes legales de la responsabilidad civil y del Seguro Obligatorio de Accidentes de Tránsito (en adelante SOAT).

55 Hohfeld, W. N. Conceptos juridicos fundamentales. Traducción de Genaro R. Carrió. Buenos Aires: Centro Editor de América Latina, 1968, pp. 67-80.

56 Terranova, Giuseppe. "La struttura delle situazioni soggettive: contributo ad una semántica dellobbligon. Europa e Diritto privato, fascículo 2, Milano, 2002, p. 549.

5. Proto PISANI, Andrea. Le tutele giurisdizionali dei diritti, Studi. Nápoles: Jovene Editore, 2003, p. 207.

§ La ley 27181 fue publicada el 08 de octubre de 1999 en el diario oficial El Peruano. 
El artículo 29 indica qué responsabilidad civil derivada de los accidentes de tránsito causados por vehículos automotores es objetiva, de conformidad con lo establecido en el Código Civil. Luego, en el numeral 30.1 del artículo 30, establece imperativamente que todo "vehículo automotor que circule en el territorio de la República debe contar con una póliza vigente del SOAT, según los términos y montos establecidos en el reglamento correspondiente». Y para que no quede duda de que el régimen legal del SOAT es diferente del régimen legal de la responsabilidad civil, se determina en el numeral 30.2 del artículo 30 que el SOAT "cubre a todas las personas, sean ocupantes o terceros no ocupantes, que sufran lesiones o muerte como producto de un accidente de tránsito".

El Reglamento Nacional de Responsabilidad Civil y Seguros Obligatorios por Accidentes de Tránsitos9 (en adelante Reglamento del SOAT) regula la responsabilidad civil derivada de accidentes de tránsito terrestre, así como el régimen y características del seguro obligatorio por accidentes de tránsito, en el marco de la ley 27181. Las normas jurídicas que regulan la responsabilidad civil ${ }^{60}$ y el SOAT son de distinta naturaleza jurídica, y por eso, en un caso, el causante tendrá el deber de pagar el resarcimiento por los daños sufridos y en el otro caso existirá la obligación de pagar la indemnización.

El seguro es "el contrato según el cual el asegurador, a través del pago de una contraprestación llamado prima, se obliga a indemnizar (rembolsar) al asegurado, dentro de los límites convenidos, del daño sufrido por el siniestro o a pagar un capital o una renta al verificarse el evento referente a la vida humana». ${ }^{61}$

9 El Texto Único Ordenado del Reglamento Nacional de Responsabilidad Civil y Seguros Obligatorios por Accidentes de Tránsito fue aprobado por decreto supremo 024-2002MTC y modificado por decreto supremo 001-2004-MTC.

w Morales Hervias, Rómulo. "Responsabilidad por incumplimiento de obligaciones de las Administradoras de Fondos de Pensiones». Revista jurídica del Perú, año LIV, n. ${ }^{\circ} 55$, febrero, 2004, p. 139: "Hay dos tipos de responsabilidad en el campo del derecho privado. La responsabilidad por incumplimiento de obligaciones y la responsabilidad aquiliana o extracontractual.

La responsabilidad por incumplimiento de obligaciones es la situación atribuida al deudor ante el incumplimiento de una obligación, es decir, ante la inejecución o ejecución parcial o tardía de la prestación. Este supuesto está regulado en los artículos 1314 y siguientes del CC.

La responsabilidad aquiliana o extracontractual es la sanción que el ordenamiento jurídico prevé contra hechos jurídicos lesivos de la integridad de las situaciones jurídicas protegidas erga omnes por el ordenamiento. A este supuesto, también se le denomina responsabilidad "aquiliana», en referencia a la lex Aquilia, aprobada por plebiscito no antes del 286 a.C. que sancionaba con penas pecuniarias las hipótesis de daños a las cosas de otros, y está normada en los artículos 1969 y siguientes del CC».

6 Gazzoni, op. cit., p. 1215. 
En el caso del seguro contra daños, prevalece la función indemnizatoria. De esta manera, las reglas sobre el seguro están orientadas en el sentido de «impedir que el instrumento asegurador sea hábilmente manipulado para conseguir un enriquecimiento indebidom. ${ }^{62} \mathrm{La}$ «indemnización debida por el asegurador nunca puede superar el daño sufrido por el aseguradom. ${ }^{63}$

«En el desarrollo de la relación rige el principio indemnizatorio según el cual el asegurador está obligado a indemnizar (el legislador usa el verbo resarcir pero impropiamente porque no se reconoce ningún ilícito) el daño sufrido por el asegurado como consecuencia del siniestrom. ${ }^{64}$

Este principio indemnizatorio implica de "tener indemne al asegurado de una pérdida, el seguro no puede resolverse en una gananciam. ${ }^{65}$ En efecto, «la indemnización debida al asegurador no puede en nigún caso superar la entidad del daño efectivamente sufrido" ${ }^{66}$

Por eso, es más propio denominar "derecho de resarcimiento" a aquel derecho que tiene la víctima en el régimen legal del CC, y «derecho de indemnización" al que tienen los beneficiarios del SOAT:

En realidad, creo que si en algo se puede mejorar el lenguaje técnico entre nosotros, lo ideal sería utilizar "resarcimiento", como en italiano (risarcimento) únicamente para la reparación de un daño a título de responsabilidad civil, e «indemnización", como en italiano (indennizo, aunque la similitud sea menor), para las cantidades que se abonan, no por la comisión de un hecho ilícito, sino en virtud de los más diversos títulos (como la suma que se paga en virtud de un contrato de seguro, donde el origen de la obligación no es legal, ni tiene su raíz en la imputabilidad del daño a sujeto que paga, es decir, la compañía de seguros, sino la voluntad de las partes). ${ }^{67}$

62 Bigliazzi Geri, Lina; Umberto Breccia, Francesco D. Busnelli, y Ugo Natoli. Diritto Civile, Obbligazioni e contratti. Turín: UTET, 1996, volumen 3, p. 535.

63 TRIMARCHI, Pietro. Istituzioni di diritto privato. Milán: Giuffré, 2003, p. 440.

64 GAZZONi, op. cit., p. 1221. El autor critica el uso del verbo «resarcir» en lugar del verbo «indemnizar» que usa el legislador italiano en el artículo 1905 del Código Civil italiano: "Límites al resarcimiento.- El asegurador está obligado a resarcir en los modos y en los límites establecidos por el contrato, el daño sufrido por el asegurado como consecuencia del siniestro.El asegurador responde del provecho esperado sólo si se ha obligado expresamenten. Esta crítica es sustentable plenamente, ya que la obligación de indemnización es el efecto que surge como consecuencia de la producción del daño en el asegurado.

6 ZATTI, Paolo y Vittorio COLUSI. "I contratti di prestazione d'opera o di servizi». En Lineamenti di diritto privato..., p. 572.

ob Gallo, Paolo. Istituzioni di diritto privato. Turín: G. Giappichelli Editore, 2003, p. 364.

6 LEÓN, Leysser. "La importancia del Derecho comparado en la reforma del Código Civil y en la formación de una verdadera Escuela de civilistas peruanos, A propósito de la modernización del Derecho de Obligaciones en Alemania (Schuldrechtsmodernisierung)». lus et Veritas, año XIII, n. ${ }^{\circ} 26,2003$, p. 45. 
La responsabilidad civil es una tutela jurídica cuya tarea es «trasladar un daño de un sujeto a otrom. ${ }^{68}$ Por eso, la víctima tiene un derecho al resarcimiento frente a un deber de resarcimiento atribuido al causante del daño. Por el contrario, en el SOAT los beneficiarios son establecidos por el Reglamento del SOAT:

Las normas del seguro obligatorio de accidentes indican las personas que tendrán la calidad de beneficiarios de la indemnización por muerte. Normalmente en los seguros que cubren el riesgo de muerte es el asegurado el llamado a designarlos, lo cual no es posible en el seguro obligatorio de accidentes. Debe ser la norma la que determine quiénes serán los beneficiarios, los cuales pueden no corresponder a las personas que, en la órbita de la responsabilidad civil, sufren un daño por rebote (si el daño es propio) o ejercen la acción hereditaria derivada de la víctima directa. ${ }^{69}$

Según el artículo 34 del decreto supremo 024-2002-MTC, las siguientes personas tenían "derecho a la indemnización":

a) El cónyuge sobreviviente;

b) Los hijos menores de dieciocho (18) años, o mayores de dieciocho (18) años incapacitados de manera total y permanente para el trabajo;

c) Los hijos mayores dieciocho (18) años;

d) El padre y/o madre de la persona fallecida;

e) A falta de las personas indicadas precedentemente, la indemnización corresponderá a quien acredite la calidad de heredero del fallecido y, si no hubieran beneficiarios ni herederos, el monto de los beneficios se destinarán al Fondo de Compensación de Seguros.

Luego, esta norma se modificó conforme al artículo 6 del decreto supremo 01-2004-MTC, y los beneficiarios del SOAT son los siguientes en el siguiente orden de precedencia:

a) El cónyuge sobreviviente.

b) Los hijos menores de dieciocho (18) años, o mayores de dieciocho (18) años incapacitados de manera total y permanente para el trabajo.

c) Los hijos mayores de dieciocho (18) años.

d) Los padres.

* MONATERı, Pier Giuseppe. La responsabilità civile. Turín: UTET, 1998, p. 16.

69 OSSA GÓmez, J. Efren y Juan Manuel DIAZ-Granados. "El seguro obligatorio de responsabilidad civil automoviliaria versus el seguro obligatorio de accidentes de tránsito". En Congreso iberoaméricano de Derecho de seguros realizado en Bogotá del 23 al 26 de agosto de 1989. Bogotá: Memorias, Unión de Aseguradores Colombianos, 1999, p. 176. 
e) Los hermanos menores de dieciocho (18) años, o mayores de dieciocho (18) años incapacitados de manera total y permanente para el trabajo.

f) A falta de las personas indicadas precedentemente, la indemnización corresponderá al Fondo de Compensación de Seguros, una vez transcurrido el plazo de prescripción liberatoria que indica la póliza del Seguro Obligatorio de Accidentes de Tránsito.

Como se puede apreciar, hubo dos cambios fundamentales. Se ha incorporado el rango cinco a los «hermanos menores de dieciocho (18) años, o mayores de dieciocho (18) años incapacitados de manera total y permanente para el trabajo». Otro cambio fundamental es haber derogado la posibilidad de pedir la indemnización a quien acredite la calidad de heredero del fallecido. Pensamos que esta derogación es congruente con la naturaleza jurídica del "derecho a la indemnización según el Reglamento del SOAT" a diferencia del «derecho al resarcimiento según el CC» que tienen los herederos conforme las normas del derecho de sucesiones que regula las transmisiones patrimoniales por causa de muerte. El CC establece reglas para la constitución, la regulación o la extinción de las relaciones jurídico patrimoniales mortis causa mediante sucesiones testadas o intestadas. En este sentido, ante un caso concreto del SOAT se debe aplicar la ley 27181 y el Reglamento del SOAT y supletoriamente las normas del $\mathrm{CC}^{70}$

El análisis de la normativa del SOAT nos demuestra que la indemnización es diferente al resarcimiento. ¿Cuál es el significado que debemos otorgar a las expresiones "indemnizar" e «indemnización" utilizadas en los artículos 1470 al 1472 del CC? En el siguiente numeral desarrollaremos la naturaleza jurídica del contrato de promesa del hecho de un tercero para determinar si estamos en un supuesto de una obligación de "resarcir" o de "indemnizar". ¿El promitente debe pagar un "resarcimiento" o una "indemnización"? Las respuestas a estas preguntas son fundamentales para determinar el régimen legal aplicable a este tipo de contrato.

\section{El significado de la promesa como compromiso de protección del estipulante}

La promesa del hecho de un tercero es un contrato entre el promitente y el estipulante. El tercero no es parte en este contrato y por eso no está obligado frente al promitente ni al estipulante. El contrato «es funcional a la

to Artículo Ix del Título Preliminar del Código Civil del Perú.- «Las disposiciones del Código Civil se aplican supletoriamente a las relaciones y situaciones jurídicas reguladas por otras leyes, siempre que no sean incompatibles con su naturaleza". 
exigencia merecedora de protección de predisponer un conjunto de intereses obviamente eficaz inter partes (por eso plenamente congruente respecto al señalado canon de la relatividad de los efectos contractuales) en todo o en parte "subordinado" (en sentido atécnico) al comportamiento de un tercero». ${ }^{71}$ Esta subordinación puede hacernos pensar que estamos en una situación jurídica subjetiva, diferente a la obligación, denominada "sujeción" que, por el contrario, es un término totalmente técnico. Si el tercero no realiza el hecho, «la única consecuencia de la promesa de la obligación o del hecho del tercero será esta: deberé indemnizar a quien he hecho la promesa, aun cuando haya empleado todo medio para inducir al tercerom. ${ }^{72}$

Además, «el presupuesto que justifica la indemnización como sanción legal de la promesa está, por lo tanto, en una suerte de intercambio entre promesa y prestación del promisario, o, más exactamente, en una reciprocidad de sacrificios económicos, derivada de una elección conscientem. ${ }^{73} \mathrm{Se}$ gún esta concepción, es perfectamente distinguible la indemnización y el resarcimiento. En el caso de la promesa del hecho del tercero hay

[...] la obligación de indemnizar, que implica la restitución de una parte de la riqueza gastada o perdida por el promisario por la iniciativa emprendida y que constituye el efecto legal de la declaración, una vez verificada la ausencia del hecho ajeno, y el resarcimiento, que representa el valor del daño, que comprende todas las consecuencias (inmediatas y directas) derivadas del incumplimiento de una obligación de hacer, daño que podrá ser resarcido según las reglas del ilícito contractual sólo si el promitente es responsable, porque, con culpa o con dolo, ha impedido el evento. ${ }^{74}$

Este argumento puede ser objetado en el sentido que, en el fondo, estamos en un supuesto de responsabilidad objetiva como se establece en el caso de las garantías implícitas que debe prestar el proveedor frente al consumidor ${ }^{75}$ o en las mal denominadas «obligaciones de saneamiento". Por eso, ahora se entiende cuando se dice que

$\pi$ CARRESI, Franco. "ll contratto». En Trattato di Diritto Civile e Commerciale. Milán: Giuffrè, 1987, volumen XXI, tomo II, p. 670.

$\pi$ TORRENTE, Andrea y Piero SCHLESINGer, Manuale di diritto privato. Milán: Giuffrè, 2004, p. 512.

3 CheCCHINI, Aldo. "La promessa del fatto del terzo (Art. 1381 C.C.)*. En /I contratto in generale, Trattato di diritto privato, volumen xul. Turín: G. Giappichelli Editore, 2002, tomo v, p. 397.

74 CHECCHINi, op. cit., pp. 419-420.

万) Artículo 41 del Decreto Legislativo $N^{\circ} 716$, Ley de Protección al Consumidor, fue modificado por la Ley $N^{\circ}$ 27311, Ley de Fortalecimiento del Sistema de Protección del Consumidor.- "Los proveedores son objetivamente responsables por infringir las disposiciones contenidas en la presente Ley. Los proveedores infractores podrán ser sanciona- 
[...] la doctrina más avanzada ha ido perfilando la llamada prestación de garantía revitalizando el concepto romano del praestare (que concibieron los romanos al lado del dare y del facere) para aglutinar a toda esta nueva categoría de relaciones caracterizados por la atribución de una garantía por riesgos (que algunos como Barassi llaman garantías impropias) dentro de las cuales se incluyen, por ejemplo, aquellas a que se refieren los artículos $1212,{ }^{76} 1213,{ }^{77} 1438^{78}$ así como las que nuestro código conoce con el nombre de Obligaciones de Saneamiento (artículo 1484 y siguientes). ${ }^{79}$

dos administrativamente con una Amonestación o con una Multa, hasta por un máximo de 100 (cien) Unidades Impositivas Tributarias, sin perjuicio de las medidas correctivas a que se refiere el artículo siguiente, que se dicten para revertir los efectos que las conductas infractoras hubieran ocasionado o para evitar que éstas se produzcan nuevamente en el futuro.

La imposición y la graduación de la sanción administrativa a que se refiere el párrafo precedente será determinada atendiendo a la gravedad de la falta, el daño resultante de la infracción, los beneficios obtenidos por el proveedor, la conducta del infractor a lo largo del procedimiento, los efectos que se pudiesen ocasionar en el mercado y otros criterios que, dependiendo del caso particular, considere adecuado adoptar la Comisión.

Las multas impuestas constituyen en su integridad recursos propios del INDECOPI, salvo por lo dispuesto en el artículo 450 de la presente Ley».

Bullard, Alfredo. "La asimetría de la información. A propósito del dolo omisivo". En Contratación contemporánea, Teoría general y principios, Instituciones de derecho privado. Santa Fe de Bogotá: Temis, 2000, p. 317: «No importa que sabía y que calló el proveedor; siempre será responsable por los daños que sus productos causen». En un sentido distinto: ESPINOZA ESPINOZA, Juan. Derecho de la responsabilidad civil. Lima: Gaceta Jurídica, 2003, p. 118: "[...I la responsabilidad objetiva administrativa, para la Ley de Protección al Consumidor, no es más que una presunción iuris tantum de responsabilidad (a la cual no se le ha dado un término feliz) que puede ser disuelta, no sólo acreditando los supuestos de ruptura del nexo causal, sino también, probando que el proveedor (en el caso de prestación de servicios) actuó utilizando la diligencia requerida. Por lo tanto, es cosa bien diversa de la responsabilidad objetiva diseñada en el Código Civil".

ऋ Artículo 1212 del Código Civil peruano.- "El cedente está obligado a garantizar la existencia y exigibilidad del derecho cedido, salvo pacto distinto".

\# Artículo 1213 del Código Civil peruano.- «El cedente no está obligado a garantizar la solvencia del deudor, pero si lo hace, responde dentro de los límites de cuanto ha recibido y queda obligado al pago de los intereses y al reembolso de los gastos de la cesión y de los que el cesionario haya realizado para ejecutar al deudor, salvo pacto distinto".

刃 Artículo 1438 del Código Civil peruano.- «El cedente garantiza al cesionario la existencia y validez del contrato, salvo pacto en contrario. Este pacto no surte efecto si la invalidez se debe a hecho propio del cedente.

Es válido el pacto por el cual el cedente garantiza el cumplimiento de la obligación del deudor, en cuyo caso responde como fiador.

El cedido puede oponer al cesionario y éste a aquél las excepciones y medidas de defensa derivadas del contrato, pero no las fundadas en otras relaciones con el cedente, salvo que expresamente hubiera hecho reserva de ellas en el momento en que aceptó la cesión».

T) FORNO, op. cit., p. 50. y por eso expresa que el «riesgo, en efecto, consistía precisamente en que el evento temido podía ocurrir en daño del promisario, y a la indemnización fue 
Debemos establecer con claridad que tanto en la responsabilidad objetiva por infracción de la Ley de Protección al Consumidor como las «obligaciones de saneamiento» ${ }^{80}$ no son comparables con la naturaleza jurídica del contrato de promesa del hecho de un tercero. Tampoco podemos asimilarlo al contrato de seguro. ${ }^{81}$ En tales supuestos, debe producirse un daño para que se produzcan las protecciones al consumidor, al comprador y al asegurado. Pero en el contrato de promesa del hecho de un tercero es indiferente que se produzca un daño y por ello es erróneo decir que existe una "prestación de garantía", simplemente lo que otorga el ordenamiento jurídico al promisario es una tutela jurídica sustancial denominada indemnización por la no realización del hecho de un tercero al igual como las garantías normadas en los artículos 1212,1213 y 1438 del CC.

\section{Conclusión}

La promesa del hecho de un tercero es un contrato por el cual el promitente asume el riesgo frente al promisario que el tercero hará un hecho. Esta promesa es una garantía que asume el promitente como consecuencia de la naturaleza jurídica del contrato del hecho de un tercero el cual es un contrato autónomo de garantía. Este contrato es parte de la relación entre poder (derecho potestativo de indemnización) y sujeción:

Naturalmente, tales sujeciones y poderes se desarrollan en el tiempo, ya que presuponen la falta de colaboración del deudor, o la verificación de otros hechos (la insolvencia) que pueden modificar el régimen de las modificaciones jurídicas normado al servicio del acreedor. Precisamente por esto, para describir las características de una relación, es necesario examinarla en una perspectiva diacrónica en la cual las situaciones subjetivas elementales, de poder y de sujeción, se actualizan, al verificarse determinadas condiciones que las hacen concretas. ${ }^{82}$

pactada para mantenerlo indemne en esa eventualidad y por ello no puede hablarse de imposibilidad sobrevenida ni de causa no imputable».

\& LUMinOSO, Angelo. "I contratti tipici e atipici». En Trattato di diritto privato. Milán: Giuffrè, 1995, p. 120: «El fundamento de tal especial responsabilidad está determinado por la objetiva inactuación o imperfecta actuación del efecto traslativo, derivada de anomalías preexistentes a la compraventa».

at FORNO, op. cit., p. 50: "El contrato de seguro de crédito (tipo muy parecido a la fianza) y el seguro en general, así como el saneamiento son formas de actuar la función de garantía. El contrato de promesa es también un tipo de contrato de garantía».

82 TeRranova, op. cit., p. 549. 
En el caso que no se efectúe el hecho del tercero, el promitente esta en una situación de sujeción de asumir el pago de una indemnización en el monto del valor económico del coste del hecho del tercero. Nótese que el pago que debe realizarse no es a título de "resarcimiento" porque no ha incumplido ninguna obligación. $\mathrm{La}$ indemnización no tiene ningún punto de contacto con el resarcimiento de los daños que el promisario sufra como consecuencia de la no ejecución del hecho por parte del tercero. Por el contrario, el promisario tendrá un derecho potestativo de exigir el pago de la indemnización en el caso de que el tercero no haga el hecho aunque no haya sufrido un daño. El promitente estará en una situación jurídica de sujeción cuando el promisario ejercite su derecho potestativo de indemnización, el cual es, en el fondo, una tutela jurídica sustancial. 